\title{
A Rarely Seen Phenolato and Azido-Bridged Polymeric Cadmium(II) Complex Derived from 2-Bromo-6-[(2-isopropylaminoethylimino)methyl]phenol
}

\author{
Guo-Ping Cheng, ${ }^{1}$ Ling-Wei Xue ${ }^{1, *}$ and Cai-Xia Zhang ${ }^{2}$ \\ ${ }^{1}$ College of Chemistry and Chemical Engineering, Pingdingshan University, Pingdingshan Henan 467000, P. R. China \\ ${ }^{2}$ Coal Chemical Industry Branch of Shenhua Ningxia Coal Group, Yinchuan Ningxia 750411, P. R. China \\ *Corresponding author: E-mail: pdsuchemistry@163.com
}

Received: 03-11-2016

\begin{abstract}
A rarely seen phenolato and azido-bridged polymeric cadmium(II) complex derived from the Schiff base ligand 2-bromo-6-[(2-isopropylaminoethylimino)methyl]phenol (HL) has been prepared and characterized by elemental analysis, IR spectroscopy, and single crystal X-ray diffraction. The Schiff base ligand coordinates to the $\mathrm{Cd}$ atom through the $\mathrm{NNO}$ donor set. The $\mathrm{Cd}$ atom is hexa-coordinated in an octahedral geometry. Adjacent two $\mathrm{Cd}$ atoms are bridged by two phenolato groups generating a dimer with $\mathrm{Cd} \cdots \mathrm{Cd}$ distance of 3.475(1) $\AA$. The dimers are further linked via azido bridges forming 2D sheets parallel to the $b c$ plane.
\end{abstract}

Keywords: Self-assembly; Crystal structure; Schiff base; Cadmium complex; Thermal analysis.

\section{Introduction}

The self-assembly and construction of metal-organic frameworks is currently a hot research field due to their fascinating structures and potential applications. ${ }^{1}$ Schiff bases have long been received much attention for their preparational accessibilities, structural varieties and biological properties. ${ }^{2}$ Tri-dentate salen-type Schiff bases are capable of forming complexes with certain metal atoms which can exhibit unusual coordination, high thermodynamic stability and kinetic inertness. ${ }^{3}$ Preparation of one-, two- or three-dimensional polymeric network by suitable metal and ligand coordination is the special area of current research because of their interesting properties, such as electrical conductivity, magnetism, host-guest chemistry, molecular separation, gas storage, sensors and catalysis. ${ }^{4}$ Among the various transition and non-transition metal atoms cadmium is an extremely toxic element that is naturally present in the environment and also as a result of human activities. The development of chelating agents is essential for the treatment of cadmium intoxication. Schiff bases have been proved to be a kind of interesting chelating agents for cadmium. A number of cadmium complexes with Schiff bases have been reported. ${ }^{5}$
Cadmium(II) due to its $d^{10}$ electronic configuration, is particularly suitable for the construction of coordination polymers and networks. The spherical $d^{10}$ configuration is associated with a flexible coordination environment so that geometries of these complexes can vary from tetrahedral to octahedral and severe distortions in the ideal polyhedron occur easily. ${ }^{6}$ The terminal or blocking co-ligands, which are usually used along with the bridging ligand to complete the metal coordination sphere, can alter the supramolecular assembly and consequently the type of structure formed taking the advantage of the flexibility of the coordination sphere. ${ }^{5 a}$ A detailed study of such complexes indicates that thiocyanate ligand is readily coordinate to the $\mathrm{Cd}$ atom, either through terminal mode or through bridging modes. ${ }^{7}$ As a comparison, azide, a simi-<smiles>CC(C)NCC/N=C/c1cccc(Br)c1O</smiles>

Scheme 1. The Schiff base HL. 
lar pseudohalide group to thiocyanate, is rarely seen in the Schiff base cadmium complexes. ${ }^{8}$ As a continuation of our work on Schiff base complexes ${ }^{9}$ we report herein a rarely seen phenolato and azido-bridged polymeric cadmium(II) complex derived from the Schiff base ligand 2-bromo-6[(2-isopropylaminoethylimino)methyl]phenol (HL; Scheme 1).

\section{Experimental}

\section{1. Material and Methods}

3-Bromosalicylaldehyde and $N$-ethylethane-1,2-diamine were purchased from Fluka. Cadmium nitrate and other reagents were analytical grade and used without further purification. The Schiff base HL was prepared by the condensation of equimolar quantities of 3-bromosalicylaldehyde with $\mathrm{N}$-ethylethane-1,2-diamine in methanol. Elemental $(\mathrm{C}, \mathrm{H}$ and $\mathrm{N})$ analyses were made on a Perkin-Elmer Model 240B automatic analyser. Infrared spectrum was recorded on an IR-408 Shimadzu 568 spectrophotometer. X-ray diffraction was carried out on a Bruker SMART 1000 CCD diffractometer. Thermal analysis was performed on a Perkin-Elmer Pyris Diamond TG-DTA thermal analyses system.

Caution! Azido compounds of metal ions are potentially explosive especially in presence of organic ligands. Only a small amount of material should be prepared and it must be handled with care.

\section{2. Preparation of the Complex}

Schiff base HL (0.271 g, $1.0 \mathrm{mmol})$ was diluted by methanol $(20 \mathrm{~mL})$, to which was added with stirring a methanol solution $(10 \mathrm{~mL})$ of cadmium nitrate tetrahydrate $(0.309 \mathrm{~g}, 1.0 \mathrm{mmol})$ and an aqueous solution $(5 \mathrm{~mL})$ of ammonium thiocyanate $(0.076 \mathrm{~g}, 1.0 \mathrm{mmol})$. The mixture was stirred for $1 \mathrm{~h}$ at ambient temperature to give a colorless solution. Colorless block-shaped single crystals suitable for X-ray diffraction were formed by slow evaporation of the solution in air for a week. The crystals were filtered off and washed with cold methanol. Yield 51\% (based on HL). Analysis calculated for $\mathrm{C}_{12} \mathrm{H}_{16} \mathrm{BrCdN}_{5} \mathrm{O}: \mathrm{C}$, 32.86; H, 3.68; N, 15.97\%; found: C, 32.72; H, 3.77; N, $15.83 \%$. Selected IR data $\left(\mathrm{cm}^{-1}\right): 3266(\mathrm{~N}-\mathrm{H}), 2066\left(\mathrm{~N}_{3}\right)$, $1643(\mathrm{C}=\mathrm{N})$.

\section{3. X-ray Diffraction}

Diffraction intensities for the crystal were collected at 298(2) K using a Bruker Apex II diffractometer with MoK $\alpha$ radiation $(\lambda=0.71073 \AA)$. The collected data for the complex was processed with $\mathrm{SAINT}^{10}$ and corrected for absorption using SADABS. ${ }^{11}$ The absorption correction was applied with $\psi$-scans. ${ }^{12}$ Structure of the complex was solved by direct method using the program SHELXS-
97, and was refined by full-matrix least-squares techniques on $F^{2}$ using anisotropic displacement parameters. ${ }^{13}$ All hydrogen atoms were placed at the calculated positions. Idealized $\mathrm{H}$ atoms were refined with isotropic displacement parameters set to 1.2 (1.5 for methyl groups) times the equivalent isotropic $U$ values of the parent carbon or nitrogen atoms. The $\mathrm{C}-\mathrm{H}$ distances for $\mathrm{CH}_{2}$ and $\mathrm{CH}_{3}$ are constrained to 0.97 and $0.96 \AA$, respectively. The remaining $\mathrm{C}-\mathrm{H}$ distances are constrained to $0.93 \AA$. The crystallographic data for the complex are listed Table 1.

Table 1. Crystal and structure refinement data for the complex

\begin{tabular}{ll}
\hline Empirical formula & $\mathrm{C}_{12} \mathrm{H}_{16} \mathrm{BrCdN}_{5} \mathrm{O}$ \\
Colour; habit & Block, colorless \\
Formula weight & 438.6 \\
Temperature $(\mathrm{K})$ & $298(2)$ \\
Crystal system & Monoclinic \\
Space group & $P 2_{1} / c$ \\
Unit cell dimensions & \\
$a(\AA)$ & $12.142(1)$ \\
$b(\AA)$ & $12.492(1)$ \\
$c(\AA)$ & $10.385(1)$ \\
$\beta\left({ }^{\circ}\right)$ & $106.649(3)$ \\
$V\left(\AA^{3}\right)$ & $1509.2(3)$ \\
$Z$ & 4 \\
Density (mg cm & \\
Absorption coefficient $\left(\mathrm{mm}^{-1}\right)$ & 1.930 \\
Reflections collected & 4.097 \\
Independent reflections & 13740 \\
Observed reflections $[I>2 \sigma(I)]_{\text {Parameters/restraints }}$ & 2816 \\
$R_{1}, w R_{2}[I \geq 2 \sigma(I)]^{\mathrm{a}}$ & 2366 \\
$R_{1}, w R_{2}(\text { all data })^{\mathrm{a}}$ & $183 / 0$ \\
Goodness-of-fit & $0.0394,0.0916$ \\
\hline
\end{tabular}

${ }^{\mathrm{a}} R_{1}=\sum\left\|F_{o}|-| F_{c}\right\| / \sum\left|F_{o}\right|, w R_{2}=\left[\sum w\left(F_{o}{ }^{2}-F_{c}{ }^{2}\right)^{2} / \sum w\left(F_{o}{ }^{2}\right)^{2}\right]^{1 / 2}$

\section{Results and Discussion}

\section{1. Description of the Crystal Structure of the Complex}

An ORTEP representation of the asymmetric unit of the complex is shown in Figure 1, with selected bond distances and bond angles listed in Table 2. The Schiff base acts as a tridentate ligand and chelates the $\mathrm{Cd}$ atoms through phenolate oxygen, imino nitrogen, and amino nitrogen, forming a five-membered chelate ring N1-Cd1-N2 and a six-membered chelate ring $\mathrm{O} 1-\mathrm{Cd} 1-\mathrm{N} 1$. The coordination mode of the Schiff base ligand is similar to the tridentate Schiff bases we reported recently. ${ }^{9 b, 14}$ The phenolate group of the Schiff base ligand binds two $\mathrm{Cd}$ atoms, generating a dinuclear subunit with $\mathrm{Cd}$... Cd distance of 3.475(1) $\AA$. The dinuclear subunits are further linked through end-to-end azido bridges forming two-dimensional sheets parallel to the $b c$ plane (Figure 2). The azido- 


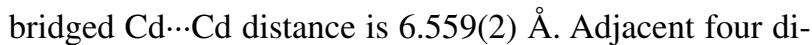
nuclear subunits are linked via end-to-end azido bridges forming a 20-membered ring with dimensions of $10.36 \AA$ $\times 6.66 \AA$ (Figure 3).

The $\mathrm{Cd}$ atoms are all six coordinated with distorted octahedral geometry having $\mathrm{N}_{4} \mathrm{O}_{2}$ donor set. The equatorial plane of the octahedral geometry is formed by phenolato oxygen (O1), imino nitrogen (N1) and amino nitrogen (N2) of the Schiff base ligand, and terminal nitrogen (N5A) of bridging azido ligand. The two axial positions are occupied by the phenolato oxygen $(\mathrm{O} 1 \mathrm{~B})$ and terminal nitrogen $(\mathrm{N} 3)$ with a trans angle, N3-Cd1-O1B, of $164.42(16)^{\circ}$. The distortion of the geometry from regular octahedron is evidenced from the respective cis- and trans-angles about the metal center. The $\mathrm{N}-\mathrm{N}-\mathrm{N}$ bond an-

Table 2. Coordinate bond distances $(\AA)$ and angles $\left(^{\circ}\right)$ for the complex

\begin{tabular}{lrlr}
\hline Bond lengths & & & \\
\hline Cd1-O1 & $2.269(3)$ & Cd1-N1 & $2.304(4)$ \\
Cd1-N2 & $2.365(4)$ & Cd1-N3 & $2.432(5)$ \\
Cd1-N5A & $2.210(5)$ & Cd1-O1B & $2.455(3)$ \\
Bond angles & & & \\
N5-Cd1-O1A & $102.24(17)$ & N5-Cd1-N1A & $174.07(18)$ \\
O1-Cd1-N1 & $77.75(15)$ & N5-Cd1-N2A & $105.72(18)$ \\
O1-Cd1-N2 & $150.96(14)$ & N1-Cd1-N2 & $75.25(16)$ \\
N5-Cd1-N3A & $92.05(19)$ & O1-Cd1-N3 & $91.63(17)$ \\
N1-Cd1-N3 & $82.04(18)$ & N2-Cd1-N3 & $95.04(18)$ \\
N5A-Cd1-O1B & $103.53(16)$ & O1-Cd1-O1B & $85.37(12)$ \\
N1-Cd1-O1B & $82.39(14)$ & N2-Cd1-O1B & $80.68(13)$ \\
N3-Cd1-O1B & $164.42(16)$ & & \\
\hline
\end{tabular}

Symmetry codes: A) $x, 1 / 2-y,-1 / 2+z$; B) $2-x, 1-y,-z$.

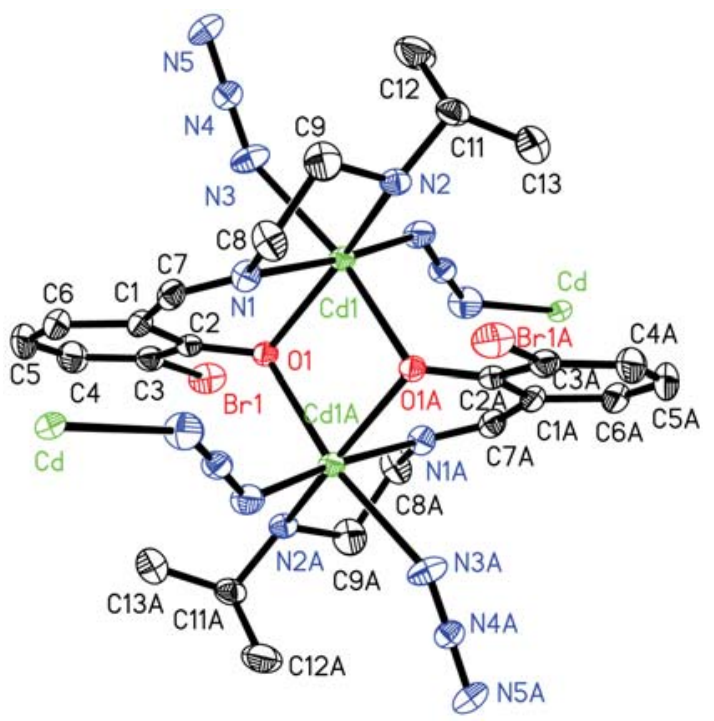

Figure 1. ORTEP view of the complex with atom labels. Displacement ellipsoids are shown at $30 \%$ probability level. The carbon hydrogen atoms are omitted for clarity. Atoms labeled with the suffix $\mathrm{A}$ are at the symmetry position: $x, 1 / 2-y,-1 / 2+z$.

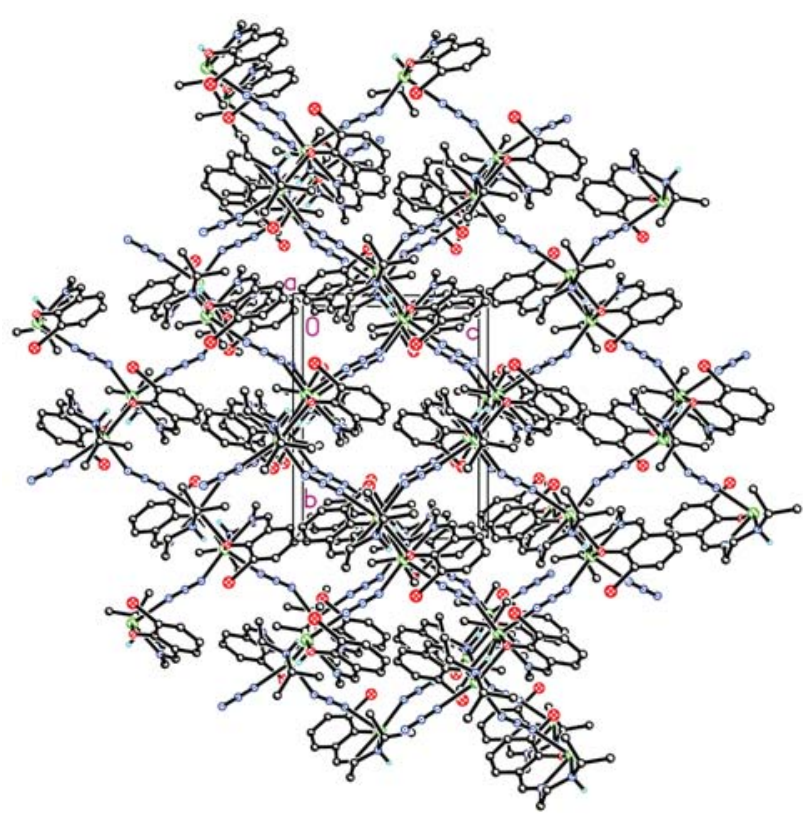

Figure 2. Crystal packing of the complex viewed along the $a$ axis.

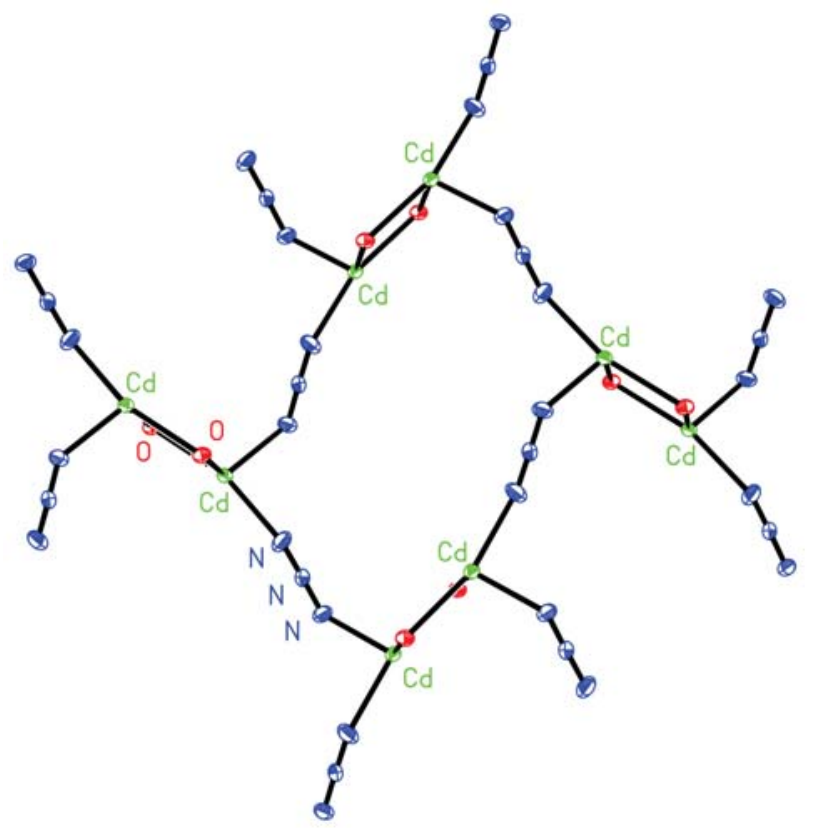

Figure 3. The azido-bridged 20-membered chelate ring.

gle in the azido ligand is $178.1(6)^{\circ}$, slightly deviated from the linearity. The $\mathrm{Cd}-\mathrm{O}$ and $\mathrm{Cd}-\mathrm{N}$ distances are within normal ranges as compared to other Schiff base cadmium complexes. ${ }^{7,8}$ As expected, the $\mathrm{Cd}-\mathrm{N}_{\text {imino }}$ is shorter than the $\mathrm{Cd}-\mathrm{N}_{\mathrm{amino}}$.

\section{2. IR Spectrum of the Complex}

The solid state infrared spectrum (Figure 4) of the complex is consistent with its crystal structure result. The 


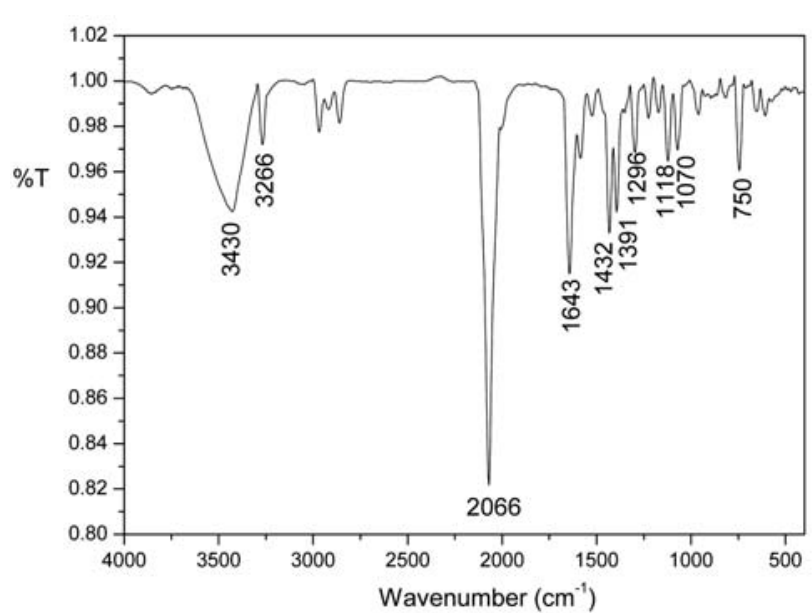

Figure 4. IR spectrum of the complex.

weak and sharp band at $3266 \mathrm{~cm}^{-1}$ is assigned to the $\mathrm{N}-\mathrm{H}$ vibration. The single and intense absorption band at 2066 $\mathrm{cm}^{-1}$ is assigned to the stretching vibrations of the azide groups. The strong absorption band centered at $1643 \mathrm{~cm}^{-1}$ is assigned to the azomethine group, $v(\mathrm{C}=\mathrm{N})$. The $v(\mathrm{Cd}-\mathrm{O})$ mode is present as a medium band at $1296 \mathrm{~cm}^{-1}$. The vibrations of the $\mathrm{Cd}-\mathrm{O}$ and $\mathrm{Cd}-\mathrm{N}$ bonds are located at the low wave numbers of $400-700 \mathrm{~cm}^{-1}$.

\section{Conclusion}

A rarely seen phenolato and azido-bridged polymeric cadmium(II) complex was obtained by reaction of 2-bromo-6-[(2-isopropylaminoethylimino)methyl]phenol with cadmium nitrate and sodium azide in methanol. The Schiff base ligand coordinates to the $\mathrm{Cd}$ atom through the $\mathrm{NNO}$ donor set, and the azido ligands bridge $\mathrm{Cd}$ atoms, to form a polymeric structure. The complex is stable up to $190{ }^{\circ} \mathrm{C}$.

\section{Supplementary Material}

CCDC-945893 contains the supplementary crystallographic data for this paper. These data can be obtained free of charge at http://www.ccd.ccam.ac.uk/const/retrieving.html or from the Cambridge Crystallographic Data Centre (CCDC), 12 Union Road, Cambridge CB2 1EZ, UK; fax: +44(0)1223-336033 or e-mail: deposit@ ccdc.cam.ac.uk.

\section{Acknowledgments}

This research was supported by the National Sciences Foundation of China (No. 20676057 and 20877036) and Top-class foundation of Pingdingshan University (No. 2008010).

\section{References}

1. (a) Z. Hulvey, D.A. Sava, J. Eckert, A. K. Cheetham, Inorg. Chem. 2011, 50, 403-405; https://doi.org/10.1021/ic101153c

(b) M. Sharma, I. Senkovska, S. Kaskel, P. K. Bharadwaj, Inorg. Chem. 2011, 50, 539-544. https://doi.org/10.1021/ic101412p

2. (a) A. Valent, M. Melnik, D. Hudecova, B. Dudova, R. Kivekas, M. R. Sundberg, Inorg. Chim. Acta 2002, 340, 15-20; https://doi.org/10.1016/S0020-1693(02)01062-9

(b) M. T. Raisanen, M. Nieger, A. M. Z. Slawin, M. Leskela, T. Repo, CryrstEngComm 2011, 13, 4701-4708; https://doi.org/10.1039/c0ce00926a

(c) S. Das, S. A. Maloor, S. Pal, S. Pal, Cryst. Growth Des. 2006, 6, 2103-2108. https://doi.org/10.1021/cg060305a

3. S. Basak, S. Sen, C. Marschner, J. Baumgartner, S. R. Batten, D. R. Turner, S. Mitra, Polyhedron 2008, 27, 11931200. https://doi.org/10.1016/j.poly.2007.12.005

4. (a) Y. Zhu, C.-F. Wang, K. Yan, K.-D. Zhao, G.-H. Sheng, Q. Hu, L. Zhang, Z. You, J. Coord. Chem. 2016, 69, 24932499; https://doi.org/10.1080/00958972.2016.1186801

(b) H.-H. Li, Z.-L. You, C.-L. Zhang, M. Yang, L.-N. Gao, L. Wang, Inorg. Chem. Commun. 2013, 29, 118-122; https://doi.org/10.1016/j.inoche.2012.12.023

(c) H. Miyasaka, R. Clerac, T. Ishii, H.-C. Chang, S. Kitagawa, M. Yamashita, J. Chem. Soc., Dalton Trans. 2002, 1528-1534. https://doi.org/10.1039/b111094m

5. (a) S. Shit, J. Chakraborty, B. Samanta, G. Pilet, S. Mitra, J. Mol. Struct. 2009, 919, 361-365;

https://doi.org/10.1016/j.molstruc.2008.10.002

(b) H.-C. Fang, Y.-Y.; Ge, Y. Ying, S.-R. Zheng, Q.-G. Zhan, Z.-Y. Zhou, L. Chen, Y.-P. Cai, CrystEngComm 2010, 12, 4012-4016; https://doi.org/10.1039/c0ce00177e

(c) W.-K. Lo, W.-K. Wong, W.-Y. Wong, J. Guo, Eur. J. Inorg. Chem. 2005, 3950-3954;

https://doi.org/10.1002/ejic.200500362

(d) J. Chakraborty, B. Samanta, G. Pilet, S. Mitra, Inorg. Chem. Commun. 2007, 10, 40-44;

https://doi.org/10.1016/j.inoche.2006.09.002

(e) P. Chakraborty, A. Guha, S. Das, E. Zangrando, D. Das, Polyhedron 2013, 49, 12-18.

https://doi.org/10.1016/j.poly.2012.09.017

6. (a) Y.-H. Liu, H.-P. Fang, P.-C. Jhang, C.-C. Peng, P.-H. Chien, H.-C. Yang, Y.-C. Huang, Y.-L. Lo, CrystEngComm 2010, 12, 1779-1783; https://doi.org/10.1039/b920419a

(b) M. Martinez-Calvo, A. M. Gonzalez-Noya, R. Pedrido, M. J. Romero, M. I. Fernandez, G. Zaragoza, M. R. Bermejo, Dalton Trans. 2010, 39, 1191-1194; https://doi.org/10.1039/B915953C

(c) S. H. Rahaman, R. Ghosh, H.-K. Fun, B. K. Ghosh, Struct. Chem. 2006, 17, 553-559.

https://doi.org/10.1007/s11224-006-9024-2

7. (a) J. Chakraborty, S. Thakurta, B. Samanta, A. Ray, G. Pilet, S. R. Batten, P. Jensen, S. Mitra, Polyhedron 2007, 26, 5139-5149; https://doi.org/10.1016/j.poly.2007.07.038 
(b) S. H. Rahaman, R. Ghosh, G. Mostafa, B. K. Ghosh, Inorg. Chem. Commun. 2005, 8, 1137-1140; https://doi.org/10.1016/j.inoche.2005.09.015

(c) Z.-L. You, H.-L. Zhu, Z. Anorg. Allg. Chem. 2006, 632, 140-146; https://doi.org/10.1002/zaac.200500308

(d) A. A. Hoser, W. Schilf, A. S. Chelmieniecka, B. Kolodziej, B. Kamienski, E. Grech, K. Wozniak, Polyhedron 2012, 31, 241-248. https://doi.org/10.1016/j.poly.2011.09.020

8. (a) F. A. Mautner, C. Berger, M. J. Dartez, Q. L. Nguyen, J. Favreau, S. S. Massoud, Polyhedron 2014, 69, 48-54; F. A. Mautner, C. Berger, R. C. Fischer, S. S. Massoud, Inorg. Chim. Acta 2016, 448, 34-41; (c) M. A. S. Goher, F. A. Mautner, A. K. Hafez, M. A. M. Abu-Youssef, C. Gspan, A. M.-A. Badr, Polyhedron 2003, 22, 975-979.

9. (a) L.-W. Xue, Y.-X. Feng, C.-X. Zhang, Synth. React. Inorg. Met.-Org. Nano-Met. Chem. 2014, 44, 1541-1544; https://doi.org/10.1080/15533174.2013.802340

(b) X. M. Hu, G.Q. Zhao, L. W. Xue, W. C. Yang, Russ. J. Coord. Chem. 2016, 42, 418-422; https://doi.org/10.1134/S107032841605002X

(c) L. W. Xue, G. Q. Zhao, Y. J. Han, Y. X. Feng, Russ. J. Coord. Chem. 2011, 37, 262-269;

https://doi.org/10.1134/S1070328411030110

(d) F. Xu, L.-W. Xue, C.-X. Zhang, Synth. React. Inorg.
Met.-Org. Nano-Met. Chem. 2015, 45, 1678-1682; https://doi.org/10.1080/15533174.2013.865226

(e) X. M. Hu, L. W. Xue, G. Q. Zhao, W. C. Yang, Russ. J. Coord. Chem. 2015, 41, 197-201; https://doi.org/10.1134/S1070328415030045

(f) H.-L. Zhu, X.-Z. Zhang, Y. Gu, A. Liu, F. Liu, Z. You, Y. Li, Acta Chim. Slov. 2016, 63, 721-725.

10. SMART and SAINT, Area Detector Control and Integration Software, Madison (WI, USA): Bruker Analytical X-ray Instruments Inc, 1997.

11. G.M. Sheldrick, SADABS, Program for Empirical Absorption Correction of Area Detector Data. Göttingen (Germany): University of Göttingen, 1997.

12. A.C.T. North, D.C. Phillips, F.S. Mathews, Acta Crystallogr. 1968, A24, 351-355. https://doi.org/10.1107/S0567739468000707

13. G.M. Sheldrick, SHELXL-97, Program for the Refinement of Crystal Structures, Göttingen (Germany): University of Göttingen, 1997.

14. (a) X.-M. Hu, L.-W. Xue, C.-X. Zhang, W.-C. Yang, Synth. React. Inorg. Met.-Org. Nano-Met. Chem. 2015, 45, 17131716; https://doi.org/10.1080/15533174.2013.867881

(b) L.-W. Xue, X. Wang, G.-Q. Zhao, Synth. React. Inorg. Met.-Org. Nano-Met. Chem. 2012, 42, 1334-13

\section{Povzetek}

Predstavljamo redek primer polimernega kadmijevega(II) kompleksa z mostovnima fenolato in azido skupinama $\mathrm{z}$ uporabo Schiffove baze 2-bromo-6-[(2-izopropilaminoetilimino)metil]fenola (HL) kot liganda. Kompleks smo okarakterizirali z elementno analizo, IR spektroskopijo in monokristalno rentgensko difrakcijo. Schiffova baza je koordinirana na Cd atom preko NNO donorskega seta. Cd atom je heksakoordiniran z oktaedrično geometrijo. Sosednja dva Cd atoma sta mostovno povezana preko dveh fenolatnih skupin, pri čemer tvorita dimer s Cd‥Cd razdaljo 3,475(1) Å. Dimeri so nadalje povezani preko azido mostov in tvorijo $2 \mathrm{D}$ plasti vzporedne $\mathrm{z} b c$ ravnino. 
